\title{
Originals
}

\section{The Influence of Glucose-Induced Hyperinsulinaemia on Renal Glomerular Function and Circulating Catecholamines in Normal Man}

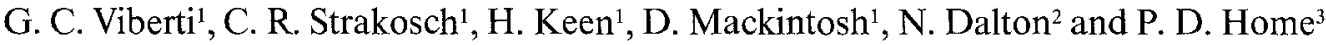 \\ ${ }^{1}$ Unit for Metabolic Medicine, ${ }^{2}$ Department of Paediatrics, Guy's Hospital Medical School, London, \\ and ${ }^{3}$ Department of Clinical Biochemistry, The Royal Victoria Infirmary, Newcastle-upon-Tyne, UK
}

Summary. The circulatory, renal, and hormonal responses to physiological elevation of plasma insulin induced with oral glucose have been studied in seven healthy subjects. Glomerular filtration rate, urinary excretion rates of albumin and $\beta_{2}$-microglobulin, haematocrit, pulse rate, blood pressure and plasma catecholamine concentrations have been measured. Physiological hyperinsulinaemia following glucose ingestion was associated with an increase in noradrenaline levels and brief tachycardia. No effect was noted on haematocrit, creatinine clearance, urinary albumin excretion, plasma adrenaline concentrations and arterial blood pressure. Urinary $\beta_{2}$-microglobulin excretion rates fell shortly after the elevation of plasma insulin, probably indicating enhanced tubular reabsorption. Thus, glucose-induced physiological hyperinsulinaemia does not reduce glomerular filtration rate nor does it increase transglomerular passage of albumin, effects seen after the intravenous bolus injection of $6-8 \mathrm{U}$ of insulin in diabetics.

Key words: Albumin, $\beta_{2}$-microglobulin, insulin, catecholamines, renal function, diabetes.

Injected doses of insulin may markedly affect the kidney and the cardiovascular system. However, such injections are usually followed by grossly supraphysiological concentrations of the hormone in the blood. In diabetics an intravenous injection of 6-8 $\mathrm{U}$ of insulin is associated with prompt decreases in forearm blood flow, renal plasma flow and glomerular filtration rate (GFR) $[1,2]$ and with increases in plasma noradrenaline levels [1,3] and pulse rate [4]. After intravenous insulin administration the plasma volume falls and the general transcapillary, as well as the transglomerular, passage of albumin increases $[1,2,5]$, though this is not found by all $[6,7]$. Such an effect of insulin or of the associated fall in blood glucose on renal haemodynamics and transglomerular passage of albumin are of potential importance for these processes might play an injurious role $[8,9]$. However, the vascular and renal changes so far reported have followed gross, transient hyperinsulinaemia induced by the intravenous injection of insulin; it is of importance to establish whether similar responses are provoked by smaller elevations of plasma insulin concentration [10-12]. We report here upon renal, sympathetic neural and cardiovascular responses to physiological hyperinsulinaemia induced by glucose ingestion in normal man.

\section{Subjects and Methods}

Consent to participate in the study was obtained from seven healthy men aged 22-37 years. They were all normotensive and all but one, who exceeded it by $18 \%$, were within $10 \%$ of ideal body weight (Statistical Bulletin Metropolitan Life Insurance Company 40: November-December 1959). Before the study, carbohydrate and sodium intakes were unrestricted. At $08.00 \mathrm{~h}$, after an overnight fast, a $17 \mathrm{G}$ teflon cannula (Venflon, Vigo) was inserted into an antecubital vein and maintained patent with isotonic saline. Subjects remained seated throughout the study except to pass urine. Every 15-20 min until the end of the experiment the subjects drank $200-250 \mathrm{ml}$ of tap water. The experiment began when a steady state of water diuresis was achieved (normally after $2 \mathrm{~h}$ ). Three consecutive $30 \mathrm{~min}$ baseline urine specimens were collected, then each subject drank a solution containing $50 \mathrm{~g}$ of glucose dissolved in $250 \mathrm{ml}$ water on one occasion and $250 \mathrm{ml}$ saline on another, the tests being performed in random order. Urine was collected every $30 \mathrm{~min}$ for the next $150 \mathrm{~min}$. Venous blood samples were taken at the midpoint of urine collection, i. e. every $30 \mathrm{~min}$ except for the first $60 \mathrm{~min}$ after the load, when sampling was every $15 \mathrm{~min}$. Withdrawn blood was replaced by equivalent volumes of normal saline. Pulse rate and arterial blood pressure were recorded by the same observer at 5 and 15 min intervals, respectively.

The following were measured: plasma glucose (glucose oxidase method, Analox GM5), urine glucose (Clinistix strips, Ames), plasma insulin [13], plasma adrenaline and noradrenaline [14], plasma and urine creatinine by autoanalyzer (Technicon, method No. SE4-0011 FH4), urine albumin and $\beta_{2}$-microglobulin concentra- 
Table 1. Urine flow in seven healthy subjects in a steady state of water diuresis before and after an oral load of glucose $(50 \mathrm{~g}$ in $250 \mathrm{ml}$ water) or of normal saline $(250 \mathrm{ml} 0.9 \% \mathrm{NaCl})$. Glucose and saline were given at 0 time

\begin{tabular}{rlr}
\hline Time $(\mathrm{min})$ & \multicolumn{2}{l}{ Urine flow $(\mathrm{ml} / \mathrm{min})$} \\
\cline { 2 - 3 } & Glucose & \multicolumn{1}{c}{ Saline } \\
\hline$-30-0$ & $10.9 \pm 0.96$ & $9.6 \pm 1.6$ \\
$0-30$ & $10.8 \pm 1.4$ & $10.2 \pm 1.6$ \\
$30-60$ & $10.5 \pm 1.4$ & $9.6 \pm 1.5$ \\
$60-90$ & $11.2 \pm 0.8$ & $11.0 \pm 1.6$ \\
$90-120$ & $12.3 \pm 1.5$ & $8.6 \pm 1.7$ \\
$120-150$ & $11.6 \pm 1.2$ & $10.3 \pm 1.5$ \\
\hline
\end{tabular}

Results are expressed as mean \pm SEM

tions by radioimmunoassay $[15,16]$. Haematocrit was measured in duplicate with a microhaematocrit centrifuge. Preliminary studies in our laboratory showed that the coefficient of variation of 20 measurements of the same sample was $0.5 \%$, i. e. a $1 \%$ change in haematocrit value could be accepted as real with $95 \%$ confidence. Urinary excretion rates were calculated from the product of concentration and timed urine volume.

\section{Statistical Methods}

Albumin, $\beta_{2}$-microglobulin and noradrenaline concentrations showed a positive skewed distribution which were normalised by conversion to $\log _{10}$ values. Observations from the three $30 \mathrm{~min}$ baseline periods were stable in each subject, so only -30 and 0 points are represented in figures. The paired Student's $t$ test was used for assessing the statistical significance of differences. Data are shown as mean \pm SEM.

\section{Results}

Urine flow was high and stable throughout the studies (Table 1). Clinistix was negative in all specimens.

\section{Plasma Glucose and Insulin Concentrations}

Glucose concentrations rose from basal values of 4.8 $\pm 0.26 \mathrm{mmol} / 1$ to peak values of $7.4 \pm 0.25 \mathrm{mmol} / 1$ at $45 \min (p<0.001)$. Basal insulin levels were $6.9 \pm$ $1.3 \mathrm{mU} / 1$ and rose to peak values of $66.3 \pm 17.4 \mathrm{mU} / 1$ by $45 \min (p<0.005)$. No change in glucose or insulin concentration occurred after saline.

\section{Plasma Catecholamines}

Plasma noradrenaline concentrations increased significantly $15 \mathrm{~min}$ after the administration of glucose and remained above baseline level until $90 \mathrm{~min}$ (Fig. 1 upper panel). In five subjects plasma noradrenaline levels started to decline at $120 \mathrm{~min}$. The two other subjects, who exerienced a sharp fall of plasma glucose below baseline following the glycaemic peak (to nadir values of 2.8 and $3.0 \mathrm{mmol} / 1$ respectively), showed a late secondary rise in noradrenaline concentrations to 2232 and $858 \mathrm{pg} / \mathrm{l}$, respectively. This heterogeneity of
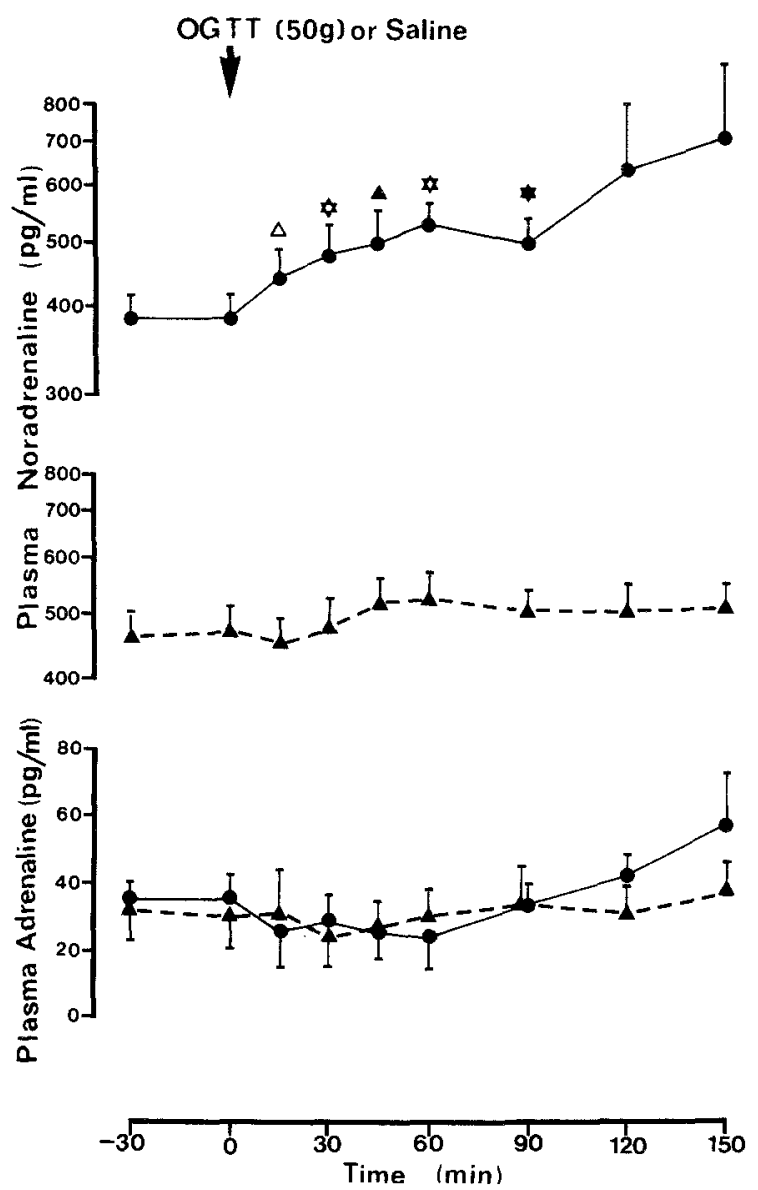

Fig. 1. Mean \pm SEM plasma noradrenaline concentrations before and after an oral load of glucose (OGTT) (upper panel) or normal saline (middle panel) in seven healthy subjects. Plasma adrenaline concentrations in the same subjects are shown in the lower panel. Symbols indicate values different from baseline: $\Delta=p<0.05$; 夜 $=p<0.005 ; \wedge=p<0.001 ; *=p<0.01 ; \bullet \bullet=$ glucose $\boldsymbol{\Lambda}-\cdots=$ saline

response is reflected by high mean values accompanied by large standard errors in pooled estimates, which rendered the differences from baseline nonsignificant. No change occurred in noradrenaline concentration after saline (Fig. 1 middle panel), and in adrenaline after either oral load (Fig. 1 lower panel). However, the two subjects with "rebound hypoglycaemia" also showed a late rise of plasma adrenaline to 90 and $97 \mathrm{pg} / \mathrm{l}$, elevating the group mean at 120 and $150 \mathrm{~min}$.

\section{Renal Function Changes and Haematrocrit}

Creatinine clearance was unaffected by either oral glucose or saline. Urinary albumin excretion rates also remained stable after both, whereas urinary $\beta_{2}$-microglobulin excretion rates decreased significantly 30 min after glucose, returning towards basal level thereafter. The haematocrit did not change significantly in either set of experiments (Fig. 2). 


\section{Pulse Rate and Blood Pressure}

Pulse rate increased significantly above a baseline of $64.8 \pm 3.2$ to $67.8 \pm 3.2$ beats $/ \mathrm{min}$ at $20 \mathrm{~min}(p<$ $0.02)$ and $68.6 \pm 3.4$ at $25 \mathrm{~min}(p<0.05)$ after glucose, and declined to baseline values by $40-45 \mathrm{~min}$. No changes were seen after saline. Arterial blood pressure was unchanged by either glucose or saline.

\section{Discussion}

Most of the renal circulatory and cardiac effects ascribed to insulin have been inferred from studies in diabetics $[1,2,4]$ in whom grossly supraphysiological plasma concentrations were induced. Changes in GFR and renal plasma flow appear to be attributable to the accompanying blood glucose responses [17]. We found no change in creatinine clearance in response to glucose-induced physiological hyperinsulinaemia, and physiological hyperinsulinaemia induced by infusion of insulin at constant, 'clamped' glycaemia provoked no alteration of GFR or renal plasma flow $[18,19]$. We were unable to demonstrate a change in haematocrit and others have failed to show significant decrease in plasma volume in diabetics after 6-10 U of insulin intravenously [6].

The urinary albumin excretion rate was unaffected by plasma insulin concentrations of the order of approximately $70 \mathrm{mU} / 1$. In keeping with this finding, Parving et al. [6] and more recently Christiansen et al. [19] failed to demonstrate an effect of insulin on the transcapillary and transglomerular passage of albumin in diabetic patients; moreover, Berglund et al. [20] showed a reduction of capillary permeability in healthy subjects with high insulin response to a glucose load. However, our results are at variance with those of Hegedüs et al. [21] who found an increase in urinary albumin excretion rates in normal subjects in response to an oral glucose load. They found that urine flow increased significantly after a glucose load; it is possible that the increased excretion of albumin in these studies was due to a wash-out effect [22]. Urinary $\beta_{2}$-microglobulin excretion fell for 30 min after the glucose load, suggesting a transient enhancement of its tubular reabsorption. During that period, therefore, an increased transglomerular passage of albumin might have been masked by an augmented reabsorption of the protein by the proximal tubule. However when $\beta_{2}$-microglobulin excretion, an index of tubular reabsorptive capacity, returned to basal there was no hint of increased albumin excretion, and therefore of increased filtration of albumin.

The consistent rise in plasma noradrenaline early during glucose absorption is in agreement with a recent report by Welle et al. [23]. Thus, either the ingested glucose or the ensuing rise in insulin levels, more
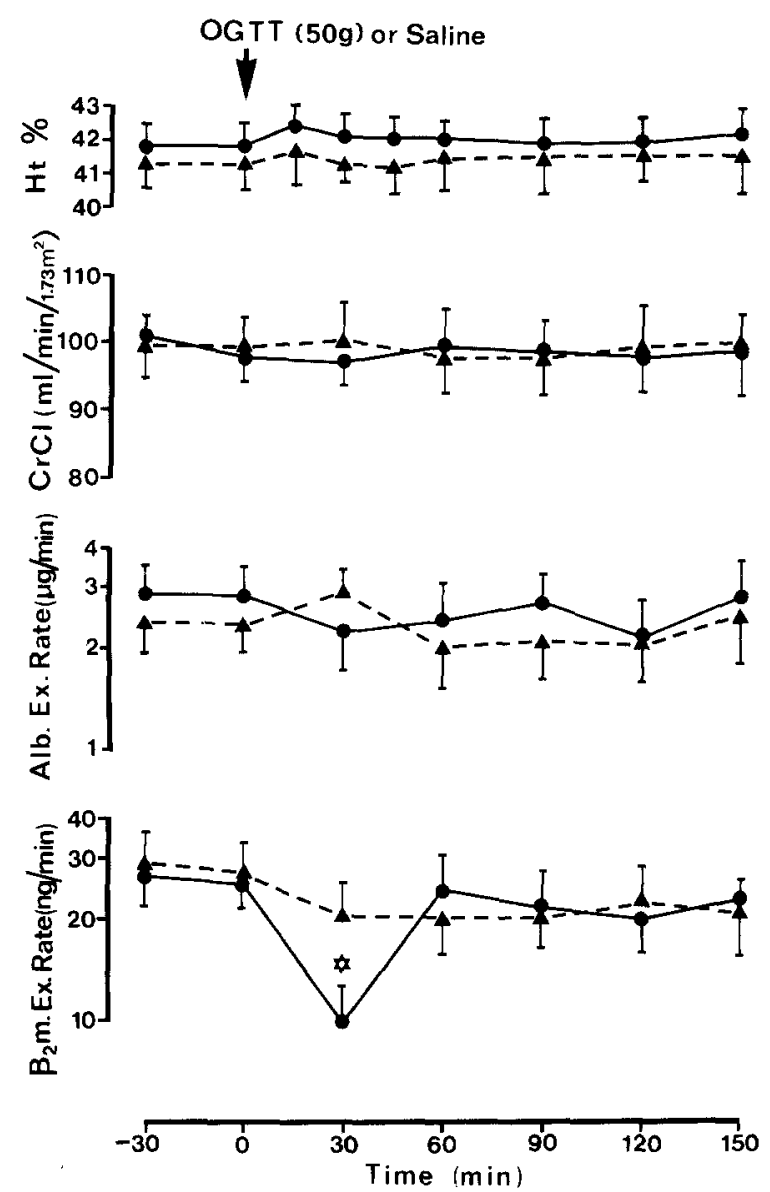

Fig. 2. Mean \pm SEM haematocrit $(\mathrm{Ht} \%)$, creatinine clearance (CrCl), albumin excretion rates (Alb. Ex. Rate) and $\beta_{2}$-microglobulin excretion rates $\left(\beta_{2}\right.$-m. Ex. Rate) in seven healthy subjects before and after an oral load of glucose (OGTT) or normal saline. $\beta_{2}$-microglobulin excretion rates were lower in the $30 \mathrm{~min}$ period after the glucose load ( $=p<0.005$ ) and returned to baseline values thereafter. $\bullet=$ glucose; $\boldsymbol{\Delta}----\mathbf{\Lambda}=$ saline

likely the latter [24], increase sympathetic nervous activity and do so independently of plasma volume changes. This increased noradrenaline concentration did not alter GFR or the transglomerular passage of albumin. However infusion of noradrenaline can produce renal circulatory changes and proteinuria in man [25], but at plasma levels of the hormone probably much higher than those recorded in our studies. Whether the renal changes observed after an intravenous bolus injection of 7-8 $\mathrm{U}$ of insulin are mediated, as suggested by Mogensen et al. [2], by a greater release of noradrenaline remains to be established.

The rise in pulse rate in normal subjects after glucose ingestion started after noradrenaline rose and returned to basal before it fell. Pulse rate acceleration after insulin may be independent of increased sympathetic nervous activity [26].

Physiological hyperinsulinaemia induced with a glucose load is necessarily accompanied by hyperglycaemia. That insulin itself may be responsible for the 
rise in noradrenaline concentrations and fall in $\beta_{2}-$ microglobulin excretion is indicated by studies in diabetics [19] and in normal subjects [24], in which blood glucose was maintained constant while insulin was raised to physiological levels of hyperinsulinaemia.

Glucagon and growth hormone have effects on renal haemodynamics which oppose those of insulin $[27,28]$. A coincident increase in their concentration might mask some of the effects of hyperinsulinaemia. However, under our experimental conditions the secretion of both hormones is likely to be suppressed $[18,29]$.

In conclusion, glucose induced physiological hyperinsulinaemia in healthy subjects with supposedly normal microvasculature is associated with stimulation of sympathetic nervous activity, a short-lasting reduction of urinary $\beta_{2}$-microglobulin excretion and pulse rate acceleration. It has no effect on plasma volume, GFR and transglomerular passage of albumin.

These data suggest that at least some of the effects of insulin (i. e. changes of the vascular permeability to albumin) on the microvasculature and renal function, in non-diabetics and diabetics alike [19], may be concentration dependent.

Acknowledgements. We thank the normal volunteers and the staff of the Peter Bishop Metabolic Ward, Guy's Hospital for their help. Dr. G. C. Viberti is a Wellcome Senior Research Fellow.

\section{References}

1. Gundersen HJG, Christensen NJ (1977) Intravenous insulin causing loss of intravascular water and albumin and increased adrenergic nervous activity in diabetics. Diabetes 26: 551-557

2. Mogensen CE, Christensen NJ, Gundersen HJG (1978) The acute effect of insulin on renal haemodynamics and protein excretion in diabetics. Diabetologia 15: 153-157

3. Christensen NJ (1974) Plasma norepinephrine and epinephrine in untreated diabetics during fasting and after insulin administration. Diabetes 23: $1-8$

4. Page MMcB, Smith RBW, Watkins PJ (1976) Cardiovascular effects of insulin. Br Med J 1: 430-432

5. MacKay JD, Hayakawa H, Watkins PJ (1978) Cardiovascular effects of insulin: Plasma volume changes in diabetics. Diabetologia 15: 453-457

6. Parving H-H, Noer I, Deckert T, Lassen NA (1979) Intravenous insulin has no effect on transcapillary escape rate of albumin and on plasma volume in short-term juvenile diabetics. Diabetes $28: 282-286$

7. Viberti GC, Haycock GB, Pickup JC, Jarrett RJ, Keen H (1980) Early functional and morphological vascular renal consequences of the diabetic state. Diabetologia 18:173-175

8. Viberti GC (1979) Early functional and morphological changes in diabetic nephropathy. Clin Nephrol 12:47-53

9. Williamson JR, Kilo C (1977) Current status of capillary basement membrane disease in diabetes mellitus. Diabetes 26: 65-73

10. Shade DS, Eaton RP, Friedman NM, Spencer WJ (1980) Normalization of plasma insulin profiles with intraperitoneal insulin infusion in diabetic man. Diabetologia 19:35-39
11. Asplin CM, Hartog M, Goldie DJ (1978) Change of insulin dosage, circulating free and bound insulin and insulin antibodies on transferring diabetics from conventional to highly purified porcine infusion. Diabetologia 14:99-105

12. Kuzuya H, Blix PM, Horwitz DL, Steiner DF, Rubenstein AH (1977) Determination of free and total insulin and C-peptide in insulin-treated diabetics. Diabetes 26:22-29

13. Hales CN, Randle PJ (1963) Immunoassay of insulin with insulin-antibody precipitate. Biochem J 88: 137-146

14. Peuler JD, Johnson GA (1977) Simultaneous single isotope radioenzymatic assay of plasma norepinephrine, epinephrine and dopamine. Life Sci 21:625-636

15. Keen $\mathrm{H}$, Chlouverakis $\mathrm{C}$ (1963) An immunoassay for urinary albumin at low concentrations. Lancet 2:913-914

16. Evrin PE, Peterson PA, Wide L, Berggård I (1971) Radioimmunoassay of $\beta_{2}$-microglobulin in human biological fluids. Scand $\mathrm{J}$ Clin Lab Invest 28:439-444

17. Mogensen CE, Christensen NJ, Gundersen HJG (1980) The acute effect of insulin on heart rate, blood pressure, plasma noradrenaline and urinary albumin excretion. The role of changes in blood glucose. Diabetologia 18:453-457

18. De Fronzo RA, Cooke RC, Andres R, Faloone GR, Davis PJ (1975) The effect of insulin on renal handling of sodium, potassium, calcium and phosphate in man. J Clin Invest 55:645-855

19. Sandahl Christiansen J, Frandsen M, Parving H-H (1981) The effect of intravenous insulin infusion on kidney function in insulin-dependent diabetes mellitus. Diabetologia 20:199-204

20. Berglund B, Efendic S, Strandell T, Luft R (1979) Capillary permeability in healthy males with different insulin response to glucose. Eur J Clin Invest 9: 363-367

21. Hegedüs L, Christensen NJ, Mogensen CE, Gundersen HJG (1980) Oral glucose increases urinary albumin excretion in normal subjects but not in insulin dependent diabetics. Scand J Clin Lab Invest 40: 479-482

22. Viberti GC, Jarrett RJ, Keen H (1977) Diuresis and urinary albumin excretion: the effect of hydration. A study in insulin-dependent diabetics and normal controls. Diabetologia 13:438

23. Welle S, Lilavivathana U, Campbell RG (1980) Increased plasma norepinephrine concentrations and metabolic rates following glucose ingestion in man. Metabolism 29:806 809

24. Rowe JW, Young JB, Stevens A et al. (1979) Insulin increases plasma norepinephrine in man independent of changes in blood glucose. Clin Res 27: 594A

25. King SE, Baldwin DS (1956) Production of renal ischaemia and proteinuria in man by adrenal medullary hormones. Am J Med 20:217-24

26. Jacobsen F, Christensen NJ (1979) Stimulation of heart rate by insulin. Uninfluenced by beta-adrenergic receptor blockade in rabbits. Scand J Clin Lab Invest 39:253-256

27. Corvalain J, Abramow M (1962) Some effects of human growth hormone on renal haemodynamics and on tubular phosphate transport in man. J Clin Invest 41: 1230-1235

28. Parving H-H, Noer J, Kehlet $\mathrm{H}$, Mogensen CE, Svendsen PAa, Heding L (1977) The effect of short-term glucagon infusion on kidney function in normal man. Diabetologia 13:323-324

29. Roth J, Glock SM, Yalow RS, Berson SA (1963) Secretion of human growth hormone: Physiologic and experimental modification. Metabolism 12:577-579

Received: 20 March 1981

and in revised form: 1 July 1981

Dr. G. C. Viberti

Unit for Metabolic Medicine

Guy's Hospital Medical School

London SE1 9RT, UK 